\title{
GESTÃO DEMOCRÁTICA: MICROPOLÍTICAS EM UMA ESCOLA MUNICIPAL DO RIO DE JANEIRO
}

\author{
DEMOCRATIC MANAGEMENT: MICROPOLITICS IN A \\ MUNICIPAL SCHOOL OF RIO DE JANEIRO
}

\section{GESTIÓN DEMOCRÁTICA: MICROPOLÍTICAS EN UNA ESCUELA MUNICIPAL DE RIO DE JANEIRO}

\author{
Andréa Casadonte ${ }^{1}$ \\ https://orcid.org/0000-0002-5137-9458 \\ Renata Telha Ferreira de Oliveira ${ }^{2}$ \\ https://orcid.org/0000-0002-9385-5109
}

\footnotetext{
${ }^{1}$ Universidade Federal do Rio de Janeiro/ Secretaria Municipal de Educação, Rio de Janeiro, Rio de Janeiro - Brasil. E-mail: andreacasadonte2@gmail.com.

${ }^{2}$ Universidade Federal do Rio de Janeiro/ Secretaria Municipal de Educação, Rio de Janeiro, Rio de Janeiro- Brasil. E-mail: renatatelha@gmail.com.
}

\section{Resumo}

O presente artigo propõe abordar algumas reflexões e tensões sobre a relação entre gestão democrática escolar e a produção de micropolíticas. Para isso relata aspectos observados em uma escola pública da rede municipal do Rio de Janeiro e traça alguns deslocamentos sobre o "conceito de gestão democrática", baseando-se no ciclo de políticas de Ball e Bowe (1992). O intuito é ecoar como os arranjos políticos e o funcionamento das micropolíticas fazem emergir arenas de disputas internas e até mesmo a ambivalência da noção de gestão democrática. Trazer a escola para este texto ajuda-nos a pensar sobre diferentes aspectos da micropolítica no contexto da prática: o funcionamento das disputas políticas que constituem o processo de gestão na unidade escolar, dos quais emergem negociações e conflitos, evidenciando não só as relações de poder em que se dão.

Palavras-chave: Gestão Democrática. Micropolíticas. Contexto da Prática.

\section{Abstract}

This paper proposes to discuss some reflections and tensions about the relationship between democratic management and the production of micropolitics. For this, it reports aspects observed in a public school in the City of Rio de Janeiro and traces some displacements on the "concept of democratic management", based on Ball e Bowe's policy cycle approach (1992). Through the observation of the interior of the school, our intention is to echo how the political arrangements and the operation of micropolitics emerge from internal disputes and even the 
ambivalence of the notion of democratic management. Bringing school to this text helps us to think about different aspects of micropolitics in the context of practice, namely: the functioning of the political disputes that constitute the management process in the school unit, from which negotiations and conflicts emerge, evidencing not only the relations of power in which they occur.

Keywords: Democratic Management. Micropolitics. Practice.

\section{Resumen}

El presente artículo propone abordar algunas reflexiones y tensiones sobre la relación entre gestión democrática escolar y la producción de micropolíticas. Así, relata aspectos observados en una escuela pública de la red municipal de Rio de Janeiro y plantea algunos desplazamientos sobre el "concepto de gestión democrática", basándose en el ciclo de políticas de Ball e Bowe (1992). Nuestro propósito es de resaltar cómo los arreglos políticos y el funcionamiento de las micropolíticas hacen emerger arenas de disputas internas e incluso la ambivalencia de la noción de gestión democrática. Traer la escuela para este texto nos ayuda a pensar sobre diferentes aspectos de la micropolítica en el contexto de la práctica: el funcionamiento de las disputas políticas que constituyen el proceso de gestión en la unidad escolar, de las cuales emergen negociaciones y conflictos, evidenciando no sólo las relaciones de poder en que se dan.

Palabras clave: Gestión Democrática. Micropolítica. Contexto de la Práctica.

\section{Introdução}

O presente artigo propõe participar do debate sobre gestão democrática escolar, oferecendo algumas questões que podem contribuir para deslocar a atenção para outros pontos dessa ampla discussão baseada na problematização do cumprimento do artigo 14 da Lei de Diretrizes e Bases da Educação Nacional (LDBEN) (BRASIL, 1996), sobre o qual têm sido produzidas políticas públicas como forma de responder, por exemplo, ao Plano Nacional de Educação (PNE) em sua Meta 19. Por meio de seus gestores, professores, funcionários, alunos e responsáveis, propomos refletir sobre como as escolas têm produzido respostas ao entendimento de como tornar factual a gestão democrática, tornando-se importante considerar os discursos e embates políticos que as atravessam. Vale pontuar que tanto o debate sobre gestão democrática escolar quanto a demanda pela visita à escola originaram-se da disciplina Gestão e Organização Escolar de um curso de pós-graduação. Nessa mesma disciplina, coletivamente, foram elaborados os roteiros de entrevista e observação do espaço escolar.

Nesse viés, ao trazer ao debate os arranjos políticos de uma escola, delineia-se um pouco do funcionamento de suas micropolíticas, emergindo a potência produtiva das disputas internas, bem como os limites e ambivalências da noção de "gestão democrática" - aqui entre aspas por 
opção teórica, fazendo ecoar Butler (1998), como forma de demarcar que o termo estará em suspensão, designando signo de disputa política e, de tal modo, desnaturalizando-o. Assim, poderíamos perguntar: não estariam em disputa sentidos de "gestão democrática" ou mesmo de "democracia"? As escolas não produziriam seus próprios mecanismos e entendimentos do que seja "o" democrático?

Nosso interesse é, no caso deste artigo, em uma unidade escolar (UE) da rede municipal de educação do Rio de Janeiro, em como se constroem sentidos de "gestão democrática". Argumentamos que o artigo 14 da LDBEN (BRASIL, 1996), por ser vago, abre diversas possibilidades de significação do que viria a ser considerado modelo de gestão. Para desenvolver essa ideia, lançamos mão da abordagem do ciclo de políticas de Ball e Bowe (1992) que, por meio de Mainardes (2006), leva-nos a considerar o contexto de produção de textos de política, uma vez que "não são, necessariamente, internamente coerentes e claros e, podem também ser contraditórios" (MAINARDES, 2006, p. 52). Mais além, ao pensar especificamente no que tange ao contexto da prática, a escola passa a ser entendida como lócus produtivo de política a partir de sua forma de ressignificar e pôr em prática os princípios da lei em vez de má implementadora da política. Argumentamos, então, que as escolas públicas, como espaços de criação de política, são, portanto, agentes no jogo político em que estão inseridas, um jogo de inter-relações entre os diferentes níveis e contextos do processo político.

Trazer a escola para este texto ajuda-nos a pensar sobre diferentes aspectos da micropolítica, como o funcionamento das disputas políticas que constituem o processo de gestão na unidade escolar, do qual emergem negociações e conflitos, evidenciando não só as relações de poder em que se dão. Dialogando com Hall (2003), entendemos que "as posições políticas não são fixas, não se repetem de uma situação histórica a outra nem de um teatro de antagonismos a outro, sempre "em seu lugar", em uma infinita iteração" (HALL, 2003, p. 104). Com isso, entendemos que não há cristalizações na dinâmica do poder, mas que esse terceiro espaço (BHABHA, 2013) é permeado pela ambivalência da negociação, o que nos leva à amplificação do debate da "gestão democrática".

\section{Aspectos metodológicos: a escola}

Nossa inserção na UE foi realizada durante dias de atividades regulares e tinha por objetivo caracterizar os processos de ocupação dos espaços de tomada de decisão para atender 
à finalidade da avaliação de uma disciplina acadêmica. A visita fora realizada em uma das 1.537 unidades escolares da prefeitura da cidade do Rio de Janeiro, cujo acesso foi facilitado por uma colega de turma. Devido às inferências que promoveremos, não divulgaremos o nome da escola nem o bairro onde se encontra, pois há poucas escolas municipais na região. Não houve qualquer tipo de barreira (física ou humana) para nossa entrada. Após a apresentação à equipe de direção, percorremos toda a área física construída da UE, objetivando contemplar os itens descritos no roteiro de que dispúnhamos. Podemos considerar que o roteiro utilizado em nossa inserção abrangia muitas das dimensões contextuais indicadas por Ball, Maguire e Brau (2016), aos quais Mainardes (2018, p. 194) faz menção em seu texto, a saber:

\begin{abstract}
a) contextos situados: o cenário local, história da escola, fluxo de alunos, etc.; b) culturas profissionais: valores, compromissos e experiências dos professores e políticas de gestão da escola; c) contextos materiais: equipe de trabalho da escola, orçamento, prédios, tecnologia e infraestrutura; d) contextos externos: nível e qualidade de apoio das autoridades locais de educação, pressões e expectativas do contexto político mais amplo, índice e taxas a serem atingidas, rankings, exigências e responsabilidades legais, etc.
\end{abstract}

Desse modo, traremos elementos que apontam para o aspecto relacional do contexto da prática. Comecemos por uma breve apresentação da unidade escolar em questão.

Trata-se de uma escola municipal situada em um bairro residencial do subúrbio, localizado na Zona Norte da cidade do Rio de Janeiro. A escola é acessível por trem e linhas de ônibus que interligam o Centro, a Zona Oeste e a Zona Norte. Embora situada em uma rua plana, seu entorno é cercado por várias favelas, as quais estão constantemente em conflito devido às disputas entre as diferentes facções do tráfico de entorpecentes, estes com grupos de milicianos, e as ações ostensivas da Política Militar. Assim, a escola é atravessada pelos efeitos da violência, pela precariedade de serviços e por problemas ambientais e sociais graves.

Seu prédio foi inaugurado em meados da década de 1970 e, atualmente, atende a um total de 515 alunos matriculados e distribuídos em nove turmas dos anos iniciais do ensino fundamental ( $\left({ }^{\circ}\right.$ ao $5^{\circ}$ anos, 230 alunos) e 12 turmas dos anos finais ( $6^{\circ}$ ao $9^{\circ}$ anos, 285 alunos). Com três andares e 25 salas de aula, o acesso dá-se apenas por escadas. Nos fundos do terreno está a casa para o funcionário residente, com o refeitório mais à frente; ao lado do prédio, a quadra poliesportiva coberta e a sala para material de Educação Física. No andar térreo do prédio principal localizam-se: secretaria, sala da direção, sala dos professores, banheiros 
masculino e feminino, sala de recursos (fechada por falta de profissional) e um banheiro adaptado para pessoas com deficiências.

Do lado oposto estão localizadas as salas cedidas ao governo do estado para funcionamento - no turno da noite - da administração da escola estadual, cujas aulas ocorrem no primeiro andar do prédio principal, onde percebe-se maior depredação da estrutura física das salas. Há, ainda, uma sala ambiente para a disciplina de Artes, um laboratório de Informática fechado porque a maior parte dos computadores não funciona - e uma sala de leitura. Não há áreas verdes, canteiros nem jardins; só uma árvore ao lado da quadra.

O modelo atribuído ao funcionamento da UE é em turno único, ou seja, com entrada a partir das 7h10 e saída às 14h30. Na cidade do Rio de Janeiro, em 2010, foi implementada a política do turno único em 7 horas para fins de funcionamento das escolas em tempo integral, por meio da Lei $\mathrm{n}^{\circ} 5.225$, de 5 de novembro de 2010, tendo sido implantadas, no ano de 2011, em 10 escolas para atender a alunos do $7^{\circ}$ ao $9^{\circ}$ ano do ensino fundamental em caráter experimental. Nos anos iniciais, a jornada escolar dos alunos passou de 4 h30 para 8 horas diárias e, nos anos finais, 7 horas diárias. Os professores ${ }^{1}$, por concurso, dupla regência ou migração, puderam ampliar suas cargas horárias de 16 horas e/ou 22h30 para 40 horas semanais. E a matriz curricular, nessas unidades, recebeu novas disciplinas, com o intuito de desenvolver o protagonismo dos(as) estudantes e a capacidade de construir um projeto de vida, além da ampliação dos tempos de aula de Língua Portuguesa e Matemática. Os(as) alunos(as) podem escolher uma disciplina eletiva para cursar e a escola organiza os novos grupos independente do ano escolar de seus componentes.

No tocante ao provimento da gestão, a atual diretora compôs chapa como diretora adjunta para o processo de consulta à comunidade no ano de 2014. A diretora eleita naquele período aposentou-se. Assim, a diretora adjunta passou a responder pela direção geral da escola a partir de julho de 2017. Ressaltamos que a composição da chapa para a seleção de gestores contempla apenas os cargos de Diretor IV (direção geral) e Diretor Adjunto. A Resolução SME $\mathrm{n}^{\circ} 1.303$ não dispõe sobre a função de coordenador(a) pedagógico(a) como elemento de composição de chapa, aspecto que não consideramos favorável para o exercício da "gestão democrática”, já que entendemos que a função de coordenador pedagógico abarca elementos

\footnotetext{
${ }^{1}$ Quanto aos professores da escola visitada, grande parte cumpre a carga horária de 40 horas, sendo apenas três deles com carga horária de 16 horas. Sobre o Índice de Desenvolvimento da Educação Básica (IDEB) referente à avaliação ocorrida no ano de 2015 , o $5^{\circ}$ ano atingiu 5.7, embora a meta projetada tenha sido 5.8 , e o $9^{\circ}$ ano atingiu 4.6, superando a meta projetada de 4.3 .
} 
LEÃO, A. C.

constitutivos de liderança da escola, como também é de suma importância para o desenvolvimento da mesma. Quanto ao processo sucessório de 2017, a chapa inscrita foi composta com outra configuração: a coordenadora pedagógica (CP) - na função desde 2010 candidatou-se a diretora geral e a que estava respondendo pela direção geral da escola retornaria para a função de diretora adjunta.

\section{Revisão bibliográfica: algumas abordagens sobre ciclo de políticas e a análise de políticas educacionais}

“A política não é 'feita' em um ponto no tempo; em nossas escolas é sempre um processo de 'tornar-se', mudando de fora para dentro e de dentro para fora." (BALL; MAGUIRE; BRAUN, 2016, p. 15)

A citação faz ecoar algumas pistas relevantes ao considerarmos a escola o lócus de produção de micropolíticas que emergem em um jogo de inter-relações entre variados níveis e contextos. Entendendo que o campo de pesquisa em políticas educacionais no Brasil pode ser considerado relativamente novo (MAINARDES, 2006), o uso da abordagem do ciclo de políticas (BOWE; BALL; GOLD, 1992) faz-se relevante por demonstrar a complexidade que perpassa as políticas educacionais, ecoando a intersecção entre micros e macros políticas, ou seja, tal concepção teórica prioriza também a ação dos agentes envolvidos em nível local, põe em foco a complexa disputa pelo poder e pelo conhecimento, bem como a elaboração das políticas em prática, tornando crucial a ação de todos os envolvidos para a execução e a análise delas.

Ball e Bowe (1992) propõem "um ciclo contínuo constituído por três contextos principais: o contexto de influência, o contexto da produção de texto e o contexto da prática" (MAINARDES, 2006, p. 50), sobre o qual não há hierarquização. A ideia é de formação de um movimento cíclico de influência mútua, fazendo que uma modificação ao longo do processo altere o ciclo como um todo. O contexto de influência, nesse sentido, é aquele no qual as políticas públicas e os discursos políticos teriam origem. Esse contexto é fundamental por ser o momento em que a arena de disputa de interesses constitui-se por grupos hegemônicos. 
Assim, é nesse contexto que diferentes grupos se articulam e conferem legitimidade ao que diz respeito à educação, produzindo um discurso base para a política, e que ocorre a influência de organismos internacionais e de temas globais nas políticas nacionais.

O contexto da produção de um texto é o território para onde as políticas são traduzidas, articulando-se com a "linguagem do interesse público mais geral. Os textos políticos, portanto, representam a política" (MAINARDES, 2006, p. 52). Fica evidente a conexão entre os interesses de grupos hegemônicos, que exercem influências nas políticas, e os interesses da população. Esses textos podem ser contraditórios e não são necessariamente coerentes e claros. A resposta a esses textos produz consequências que são vivenciadas dentro do terceiro contexto, o da prática, em que a política pode ser interpretada e ressignificada, sendo essa a arena em que ocorrem transformações e mudanças significativas no que foi pensado como a política inicialmente. É nesse sentido que a ação é exercida pelos sujeitos nas localidades, fazendo que as políticas sejam recriadas:

Esta abordagem, portanto, assume que os professores e demais profissionais exercem um papel ativo no processo de interpretação e reinterpretação das políticas educacionais e, dessa forma, o que eles pensam e no que acreditam têm implicações para o processo de implementação das políticas. (MAINARDES, 2006, p. 53)

Seguindo o objetivo do presente artigo, ou seja, examinar a importância do contexto da prática como fonte de recomposição das políticas, argumentamos, então, que as escolas públicas se constituem como espaço de criação política. Retomamos, assim, Ball, Maguire e Braun (2016) quando afirmam que:

No centro da atuação da política está a escola - mas a escola não é nenhuma entidade
simples nem coerente. [...]. As escolas não são uma peça só. Elas são redes precárias
de grupos diferentes e sobrepostos de pessoas, de artefatos e de práticas. [...]. As
escolas são também diferentes lugares em diferentes épocas do ano, ou do dia, ou em
partes do semestre - mais ou menos carregadas ou relaxadas. As escolas são
organizações orgânicas que são, pelo menos em parte, o produto do seu contexto -
perfis de pessoal, matrículas e aspirações dos pais - bem como sendo influenciadas
por aspectos práticos, tais como o alojamento da escola, a construção e o seu ambiente
circundante. Há um contexto social e uma materialidade para a política. (BALL;
MAGUIRE; BRAUN, 2016, p. 201)

Dessa forma, erradica-se qualquer possibilidade de binarismos, uma vez que as escolas (e todos que a compõem) tornam-se agentes, mesmo que não seja de modo similar. Assim, 
fazem-se relevantes algumas problematizações: como os diferentes atores interpretam e atuam a política em contextos variados, mediante os recursos disponíveis? Como fatores "extramuros" da escola (históricos, culturais, sociais) podem afetar a forma de atuação das escolas nas políticas?

No presente texto, lançaremos mão dessas ferramentas teórico-metodológicas na tentativa de entender e potencializar o envolvimento da gestão de uma escola pública do Rio de Janeiro. Para isso direcionaremos nosso olhar para alguns tensionamentos que consideramos pertinentes ao debate, com foco na gestão da UE observada, evidenciando alguns rastros da atuação política no contexto da prática.

\section{Resultados e discussões do estudo de caso: micropolíticas, participação e gestão escolar}

Iniciamos o texto propondo o tensionamento do que frequentemente entende-se por "gestão democrática" e, a partir de um exercício de suspensão dessa categoria, atentarmos para outros possíveis espectros do debate. Para darmos prosseguimento, trazemos ao texto o conhecido trecho da LDB (BRASIL, 1996) que trata da gestão democrática:

\footnotetext{
Art. 14. Os sistemas de ensino definirão as normas da gestão democrática do ensino público na educação básica, de acordo com as suas peculiaridades e conforme os seguintes princípios:

I - participação dos profissionais da educação na elaboração do projeto pedagógico da escola;

II - participação das comunidades escolar e local em conselhos escolares ou equivalentes.
}

Sem definir normas e critérios diretivos, a lei delimita princípios do que viria a ser uma "gestão democrática". Quando se busca o entendimento dentro da própria lei sobre como definir democracia, podemos apenas caracterizá-la por meio da participação dos profissionais ou das comunidades escolar e local. No que concerne aos seus aspectos epistemológicos e/ou ontológicos, abrem-se as possibilidades das contingências para poder teorizá-la. Retomando Ball e Bowe (1992), por meio de Mainardes (2006), podemos entender que a opção pelo uso de termos abrangentes na escrita deste trabalho - como possível característica de um texto de política - emerge como efeito de uma conjugação de relações de poder e, ao mesmo tempo, 
torna possível uma série de significações e negociações pelas instituições escolares do que viria a ser "gestão democrática" e de como implementá-la. Mais do que inferir se a gestão da UE visitada é democrática ou não, desejamos trazer alguns exemplos de como essa escola faz política por meio de exemplos de práticas compartilhadas conosco em nossas visitas.

a) Quem quer participar?

Conforme apontam Arelaro, Jacomini e Carneiro (2016), a “mobilização da sociedade”, isto é, a presença da comunidade nas atividades, no Conselho Escola Comunidade (CEC), no Grêmio Escolar e em outros espaços colegiados, deve ser desenvolvida pela gestão, de modo que a comunidade se engaje nos projetos e nas instâncias decisórias, que se entendem como "democráticas" na escola. De acordo com a diretora entrevistada, tanto o CEC quanto o Grêmio existem formalmente - foram eleitos e participam das funções da escola. Há informações sobre o funcionamento do conselho e do grêmio disponíveis para a comunidade, mas não há manifestação de interesse em conhecê-las. Apesar das convocações, a frequência é baixa, conforme relato da diretora.

Soubemos, em conversa com uma professora que, na escola, as/os representantes de turma eram, por vezes, escolhidos pelos professores das turmas. Em outros anos, escolhidos pelos próprios alunos por meio de votação. Se algum(a) aluno(a) eleito(a) fosse considerado(a) inadequado(a) por questão disciplinar pelas gestoras, nova eleição era realizada ou a CP anulava a eleição e escolhia a representação. Assim, não é difícil entender por que, para dar conta da demanda por formação de um Grêmio Escolar, a solução encontrada pelas gestoras foi a seleção de alunos, convocados pela $\mathrm{CP}$, para a constituição de chapa única. As(os) aluna (os) receberam informações sobre o que era um grêmio e as funções que cada um deveria exercer, no entanto, na prática, de acordo com a informação dada por um professor, depois da eleição, as atribuições das(os) alunas(os) resumiam-se ao cumprimento de algumas tarefas cotidianas solicitadas pela $\mathrm{CP}$, como, por exemplo, transmitir recados aos professores fazendo uso de um livro de avisos; ajudar na arrumação da escola para eventos; chamar alunos até a secretaria; informar à CP sobre a conduta das/dos professoras(es) e alunas(os); recolher doação dos professores para os eventos da escola - tarefas que outros alunos, além dos membros do grêmio, também exerciam.

Para prosseguimento da eleição do CEC, de acordo com a diretora, os representantes dos segmentos Aluno e Responsável foram escolhidos e convidados pelas gestoras. Se, por um lado, tornou possível a execução do processo eleitoral, por outro poderia haver uma articulação por parte da relação de poder da gestão controlando as medidas que viriam a ser tomadas, 
votadas e decididas no CEC. Quanto ao segmento Professor, os representantes foram indicados para participação do processo eleitoral, principalmente porque já havia disponibilidade e conhecimento das tarefas burocráticas a serem realizadas como membro do CEC. Diante disto, verificamos que, embora haja o CEC eleito, sua função assume, contudo, apenas um caráter burocrático, o que também ocorre com o Grêmio Escolar.

A exigência de constituição do conselho e do grêmio emerge do contexto da produção de texto, já que são determinadas por resoluções provenientes da Secretaria Municipal de Educação, publicadas em Diário Oficial do Município; no entanto as ações praticadas pela UE se coadunam com as ideias de Ball, Maguire e Braun (2016) ao nos possibilitarem considerar um conjunto de dinâmicas e interpretações subjetivas que podem ou não ir ao encontro do contexto da produção de texto. Ou seja, no contexto da prática, a interpretação e a tradução dos textos legais incidiram em uma ressignificação não só da política de resolução de constituição do CEC e do Grêmio Escolar, como também na ressignificação do conceito de gestão democrática.

Na escola em voga, observamos também que a dimensão de coordenação é subsumida pela administração, tornando, nessa perspectiva, o fazer diretivo problemático, uma vez que a tarefa da coordenação da vida escolar é negligenciada pela direção, o que explica o fato de a coordenadora pedagógica exercer um poder político local com maior força do que a própria direção. O que nos parece é que o exercício das funções de gestão na escola é marcado por um grau muito pequeno de accountability, dentro do que propõem Ferreira e Medeiros (2016, p. 785). Em outras palavras, não existem meios, em nível local, que a façam avaliar seu modus operandi e responder por ele.

b) De quem é a gestão?

Quando consultada sobre a existência ou não de um organograma na escola, a diretora apresentou a descrição de um organograma empresarial, porém o discurso foi de igualdade de voz e vez para todos. Essa discrepância entre o discurso e a prática da diretora nos remete ao artigo de Silva (2011) que, ao tratar da contribuição das estruturas burocráticas e centralizadoras das instituições brasileiras na construção da identidade oficial dos diretores, mostrou a distância entre o que está na legislação e a interpretação e a prática concreta no cotidiano das escolas. A diretora, quando explicou o organograma, além de apresentá-lo de forma hierárquica, colocouse no topo dessa estrutura, o que muito se assemelhava com a de uma empresa, sendo seguida pela direção adjunta - no caso dessa escola não havia - e pela $\mathrm{CP}$, estando abaixo os professores, 
depois os funcionários e, em seguida, os alunos. Diante disso, notamos que em nenhum momento ela apontou que coordena em consonância com o Conselho Escolar, de tal forma que o CEC nem foi mencionado no organograma que ela apresentou.

Uma vez perguntada sobre o clima escolar, a diretora respondeu-nos que, naquele período, o clima institucional estava amigável, porém já houve momentos de tensão na relação entre professores e equipe gestora. Em conversa com duas professoras na sala dos professores sobressaiu em suas falas que parte do desgaste entre a equipe concentrava-se na figura da $\mathrm{CP}$, que não mantinha bom relacionamento com alguns funcionários, principalmente naquele período em que intencionava concorrer ao cargo diretivo.

Esse conjunto de fatores nos remete ao trabalho de Oliveira e Waldhelm (2016) acerca do exercício da liderança daqueles que estão em funções diretivas nas escolas. Ao problematizar as relações entre a liderança do diretor e o clima escolar, as autoras produzem uma série de dados cuja análise foi realizada mediante dois índices: Índice de Liderança do Diretor e Índice de Clima Escolar/Colaboração Docente. Para ilustrar nossas considerações, tomamos o primeiro desses índices como critério de análise:

Quadro 1 - Cargas fatoriais das variáveis relativas à liderança do diretor.

\begin{tabular}{|l|c|}
\hline \multicolumn{1}{|c|}{ Índice de liderança do diretor } \\
\hline Variável & Carga fatorial \\
\hline $\begin{array}{l}\text { O(A) diretor(a) discute metas educacionais com os professores nas } \\
\text { reuniões. }\end{array}$ & 0,726 \\
\hline $\begin{array}{l}\text { O(A) diretor(a) e os professores procuram assegurar que as questões } \\
\text { de qualidade de ensino sejam uma responsabilidade coletiva. }\end{array}$ & 0,751 \\
\hline $\begin{array}{l}\text { O(A) diretor(a) informa aos professores as possibilidades de } \\
\text { aperfeiçoamento pessoal. }\end{array}$ & 0,743 \\
\hline $\begin{array}{l}\text { O(A) diretor(a) dá atenção especial a aspectos relacionados com a } \\
\text { aprendizagem dos alunos. }\end{array}$ & 0,837 \\
\hline $\begin{array}{l}\text { O(A) diretor(a) dá atenção especial a aspectos relacionados com as } \\
\text { normas administrativas. }\end{array}$ & 0,731 \\
\hline
\end{tabular}




\begin{tabular}{|l|c|}
\hline $\begin{array}{l}\text { O(A) diretor(a) dá atenção especial a aspectos relacionados com a } \\
\text { manutenção da escola. }\end{array}$ & 0,765 \\
\hline O(A) diretor(a) me anima e me motiva para o trabalho. & 0,847 \\
\hline O(A) diretor(a) estimula as atividades inovadoras. & 0,828 \\
\hline Sinto-me respeitado(a) pelo(a) diretor(a). & 0,761 \\
\hline Tenho confiança no(a) diretor(a) como profissional. & 0,802 \\
\hline
\end{tabular}

Extraction Method Principal Component Analysis

Fonte: Extraído de Oliveira e Waldhelm, 2016

Observando as variáveis do quadro índice de liderança do diretor e por meio do depoimento de duas professoras que atuam na UE visitada, percebemos que as gestoras em análise não apresentam significativas preocupações com a variável que apresenta a maior carga fatorial ("o diretor me anima e me motiva para o trabalho"). Se olharmos de forma mais atenta os indicadores desse quadro e, considerando os depoimentos das gestoras, dos cinco índices de carga fatorial mais elevada, apenas o que se refere à aprendizagem dos alunos ("o diretor dar atenção especial aos aspectos relacionados com a aprendizagem dos alunos") nos pareceu ser fonte de alguma preocupação das gestoras.

Quando perguntamos sobre o Projeto Político Pedagógico (PPP) da escola, a diretora nos informou que havia sido elaborado há oito anos como uma produção intelectual da $\mathrm{CP}$ e que precisava ser revisto. Alguns professores nos informaram que a $\mathrm{CP}$ não lhes permitia realizarem qualquer alteração no PPP, somente no que tangia à lista de atividades do ano letivo. Essa postura da CP aponta a hierarquia na relação de poder por parte de sua gestão. Vale ressaltar que essa questão da produção e da aplicação do PPP na escola está fora do alcance do processo de consulta à comunidade escolar para o provimento da gestão, visto que a $\mathrm{CP}$, que possui uma autonomia relativa nesse ponto, não é eleita democraticamente junto à direção, principalmente por se tratar de alguém que ocupa o cargo há muitos anos.

De acordo com Fernández (2015), o PPP de uma organização escolar é caracterizado com uma concepção político-pedagógica da própria organização, em consonância com as políticas públicas do sistema educacional, com o intuito de criar e manter uma estrutura pedagógica que ofereça os meios pertinentes para atender, de forma coerente, aos fins da educação. Fernandez (2015, p. 43) também aponta que a literatura acadêmica apresenta a 
tendência de entender o projeto político-pedagógico como "facilitador do debate entre os diferentes sujeitos da educação escolar", além de citar os marcos legais que o mencionam, como, por exemplo, a LDBEN² (1996) e o PNE 2001-2010.

Nesse movimento, apesar de haver mais de 20 anos que a LDBEN instituiu legalmente a gestão democrática e o desenvolvimento da proposta pedagógica das organizações escolares, ainda é relevante refletir como essas propostas se consolidam nas unidades escolares, independente da necessidade legal de elaboração da referida proposta, principalmente no tocante ao contexto da prática.

Nas palavras de Fernández (2015, p. 53):

\begin{abstract}
Espera-se que o conhecimento mais detalhado dos problemas e as relações entre eles possam colaborar para a elaboração de um plano global de ação para a escola que também contenha, além de orientações gerais, propostas concretas para sua operacionalização e avaliação que, como fica evidente, não se pode restringir à avaliação discente, mas precisa incorporar outras dimensões organizacionais, inclusive o andamento do próprio projeto e seu plano de ação.
\end{abstract}

Diante do exposto, o reconhecimento dos problemas mais significativos da unidade escolar e a busca coletiva por soluções viáveis podem permitir um planejamento mais efetivo, contemplando os aspectos técnicos e políticos. Desloca-se, assim, o foco somente nos projetos didáticos para também outros planos e projetos que comumente não são discutidos ou compartilhados com todos/as envolvidos/as na organização escolar.

No caso da escola visitada, a dimensão de coordenação parece ter sido incorporada pela administração, tornando, nessa perspectiva, o fazer diretivo problemático, uma vez que a tarefa da coordenação da vida escolar é negligenciada pela direção, o que explica o fato de a coordenadora pedagógica exercer um poder político local com maior força do que a própria direção. O que nos parece é que o exercício das funções de gestão na escola é marcado por um grau muito pequeno de prestação de contas, dentro do que propõem Ferreira e Medeiros (2016, p. 785).

A CP não parecia ver-se na posição de responder por seus atos discricionários na escola. Isso ocorre porque buscava apoiar-se no único grupo que, talvez, fosse imediatamente ouvido por instâncias superiores da Secretaria Municipal de Educação: os discentes; portanto a CP

\footnotetext{
${ }^{2}$ A LDBEN (1996) utiliza o temo "projeto pedagógico".
} 
LEÃO, A. C.

dispunha de autonomia política em relação à direção escolar e sua atuação não se colocou de forma subordinada. Ao mesmo tempo, apresentou-se como hierarquicamente superior aos professores, fato que somente é possível por existirem poucos mecanismos de controle externos sobre a sua ação em nível local. Dessa forma, acreditamos que esse é o caso da CP, uma vez que os processos de supervisão e controle sobre a gestão escolar em relação àqueles que poderíamos chamar de burocratas de nível de rua (FERREIRA; MEDEIROS, 2006) são frouxos e não passam pelos membros da comunidade escolar, apresentando um elevado grau de autonomia nas suas atitudes, sem qualquer acompanhamento.

Além de todas essas questões, o PPP, como vimos, é uma produção intelectual elaborada pela CP. Apesar de encontrar-se disponível para acesso, o grupo não tem o direito de modificálo, limitando-se ao acréscimo apenas da lista de atividades do ano letivo. Ao contrário do que propõe Fernandez (2015), o PPP não contempla a definição de problemas e objetivos específicos, ele evidencia marcos discursivos educacionais genéricos e não explicita especificações. O planejamento é para o outro, e não com o outro.

\section{Considerações finais}

Paro (2015) discute novas alternativas de administração da escola básica, transcendendo a forma usual de concentrá-la nas mãos de apenas um indivíduo que se constitui chefe geral de todos e o responsável maior pela escola. A hierarquia em si pode não ser nociva quando aquele que se coloca no escalão hierárquico superior está investido de uma autoridade democrática, que reconhece as relações entre sujeitos, que tem sua subjetividade preservada e mesmo afirmada nessa relação. Assim, para o autor, parece vantajoso que a direção seja exercida por um colegiado diretivo formado por três ou quatro coordenadores que dividem entre si os encargos da direção, sem que algum seja o chefe absoluto do colegiado ou da unidade de ensino.

Nesse cenário, é relevante considerar o quanto variáveis distintas são necessárias para a construção de um modelo de gestão democrática em uma escola, já que o entendimento do que seja liderança dos diretores, da coordenação pedagógica, o clima escolar, a relação entre a direção, os profissionais que atuam na escola, a participação efetiva da comunidade do local e escolar, a composição dos espaços decisórios, entre outros fatores observados devem ser somados ao provimento da gestão por eleição, de modo que os espaços administrativo e burocrático da escola sejam democratizados. 
Propomos também o deslocamento da ideia de que a escola se configura como "mero destinatário de políticas", sendo também produtora de micropolíticas, já que a atuação dos considerados "receptores" pode ressignificar o texto da política, como também produzir outro texto no contexto da prática - como é possível notar com relação à tradução dos princípios da gestão democrática contidos na LDBEN, da constituição e do funcionamento dos espaços decisórios na unidade escolar visitada.

Ao propormos suspender os sentidos de "gestão democrática", sem intencionalmente questionarmos, à primeira vista, se a escola a pratica ou não, intentamos trazer ao primeiro plano do texto as micropolíticas que tornam possíveis discutirmos os processos de gestão a partir da lente teórica do ciclo de políticas. Para isso fizeram-se relevantes tanto a abordagem da trajetória de ocupação dos cargos diretivos como da composição das demais instâncias de tomada de decisão dessa unidade escolar, como o CEC e o Grêmio Escolar, que figuram como burocraticamente ativos, embora cotidianamente inexpressivos.

Nessa mesma direção, percebemos a configuração de forças na unidade escolar visitada quando o assunto questionado foi a elaboração e atualização do Projeto Político Pedagógico. Além de não ter sido elaborado em coletividade, mas pela coordenadora pedagógica, há oito anos, não reflete as demandas e ações para a resolução de problemas e conflitos pertinentes ao cotidiano escolar - a não ser pelo calendário de atividades e festividades anuais do PPP, passível de intervenção apenas para as professoras e os professores.

Tal relação nos possibilita, ainda, vislumbrar outro aspecto dessa distribuição de forças, quando alunos, responsáveis e funcionários não tomam a parte que lhes cabe no processo decisório, ou seja, o jogo político se estabelece com um desequilíbrio por parte da gestão, tendendo principalmente para a figura da coordenadora pedagógica, cujo processo de seleção é feito por indicação, e não por eleição, diferentemente da direção e direção adjunta. Neste caso, como quisemos fazer aparecer, os traços da política são delineados enrobustecendo a coordenadora, que, ao privilegiar as demandas discentes, cria distanciamento e tensionamento com os docentes e demais funcionários, afetando o clima escolar. Ao mesmo tempo, a direção, ciente dos conflitos, mantém o status quo, reforçando uma perspectiva burocrática da gestão escolar por meio de uma tradução hierarquizante do organograma escolar e da preponderância de uma dimensão que distinga teoria e prática no que concerne à concepção dos princípios existentes na LDBEN. 


\section{Referências}

ARELARO, L. R. G.; JACOMINI, M. A.; CARNEIRO, S. R. G. Limitações da participação e gestão democrática a rede estadual paulista. Educação e Sociedade, Campinas, v. 37, n. 137, out./dez. 2016.

BALL, S. J.; BOWE, R. Subject departments and the "implementation" of National Curriculum policy: an overview of the issues. Journal of Curriculum Studies, London, v. 24, n. 2, p. 97-115, 1992.

BALL, S. J.; MAGUIRE, M.; BRAUN, A. Como as escolas fazem as políticas: atuação em escolas secundárias. Tradução Janete Bridon. Ponta Grossa: UEPG, 2016.

BHABHA, H. O local da cultura. Tradução de Myriam Ávila, Eliana Lourenço de Lima Reis, Gláucia Renata Gonçalves. 2. ed. Belo Horizonte: Editora UFMG, 2013.

BOWE, R.; BALL, S.; GOLD, A. Reforming education \& changing schools: case studies in policy sociology. London: Routledge, 1992.

BRASIL. Lei n⿳0 9.394 de 20 de dezembro de 1996. Lei de Diretrizes e Bases da Educação Nacional. Disponível em: http://www.planalto.gov.br/ccivil_03/Leis/19394.htm. Acesso em: 7 jun. 2018.

BUTLER, J. Fundamentos Contingentes. Cadernos Pagu. Campinas: SP, n. 11, p.11-42, 1998.

FERNANDEZ, S. Projeto Político Pedagógico e cotidiano escolar: retrospectivas, deslocamentos e possibilidades. In: AMARAL, D. P. do. Gestão Escolar pública: desafios contemporâneos. Rio de Janeiro: Fundação Vale, UNESCO, 2015.

FERREIRA, V. da R. S.; MEDEIROS, J. J. Fatores que moldam o comportamento dos burocratas de nível de rua no processo de implementação de políticas públicas. Cad. EBAPE.BR, v. 14, n. 3, Artigo 1, Rio de Janeiro, jul./set. 2017.

HALL, S. Quando foi o pós-colonial? Pensando no limite. In: HALL, S. Da diáspora: identidades e mediações culturais. Belo Horizonte: Editora da UFMG, 2003, p. 116-123.

MAINARDES, J. Abordagem do ciclo de políticas: uma contribuição para a análise de políticas educacionais. Educ. Soc., Campinas: SP, v. 27, n. 94, p. 47-69, jan./abr. 2006.

MAINARDES, J. Reflexões sobre o objeto de estudo da política educacional. Laplage em Revista. Sorocaba: SP, v. 4, n. 1, p. 186-201, jan./abr. 2018.

OLIVEIRA, A. C. P. de; WALDHELM, A. P. S. Liderança do diretor, clima escolar e desempenho dos alunos: qual a relação? Ensaio: aval. pol. públ. Educ., Rio de Janeiro, v. 24, n. 93, p. 824-844, out./dez. 2016.

PARO, V. Diretor Escolar? Educador ou gerente? São Paulo: Cortez, 2015.

SILVA, J. M. A. de P. A construção da identidade de diretores: discurso oficial e prática. Educação em Revista, v. 27, n. 3, p. 211-230, dez. 2011. 
STENGERS, I. A proposição cosmopolítica. Revista do Instituto de Estudos Brasileiros, São Paulo, n. 69, p. 442-464, abr. 2018.

Recebido em: 23/11/2018

Revisado em: 26/11/2020

Aprovado em: 03/02/2021

Publicado em: 15/03/2021 